\title{
Prevention of social problems facing marginalized groups in Czech schools - a starting point to educational social work
}

\author{
M. Cichá, A. Preissová Krejčí
}

Original Articles

Department of Anthropology and Health Education,

Faculty of Education, Palacky University Olomouc, Czech Republic

Submitted: 23.6.2015 Revised: 8.2.2016 Accepted: 5.4.2016

\section{Reviewers:}

J. Nzau Mavole

The Catholic University of Eastern Africa

P. S. Czarnecki

Rector of the Warsaw Management University, Poland

\section{Key words:}

attitudes, educational social work, multiculturalism, research, values and value orientations

\section{Running headline:}

Dental infectious are one of major health care issues in Sub Saharan Africa

\section{Abstract:}

This study focused on educational social work practice consequences, specifically prevention of xenophobia and racism in Czech primary and secondary schools. The findings are from a research conducted among teachers and students of both primary and secondary schools in Zlín, Olomouc and Moravia-Silesia Regions from September 2014 to June 2015. The aim was to explore on the attitudes of teachers and young students to the ideas of multiculturalism. The presented results focus on the way multicultural education is conceived and understood. With regard to the current migration situation, the approach of both teachers and the young students to members of ethnic or religious minorities, from which Roma were the most often reflected by the two groups, seems of key importance as well.

\section{Introduction}

This study focused on educational social work practice consequences, specifically prevention of xenophobia and racism in Czech primary and secondary schools. The basis for this study is the concept of educational social work by Mária Machalová (2013). Machalová highlights the intersection of the aspects of social work related to the pedagogical sciences: social education and social andragogy. The intention of educational social work is to interlink the educational process, as well as lifelong learning, while solving social problems (Machalová, 2013, p. 21-23). An inspiration may be provided by critical pedagogy 
of Paulo Freire (1986), which has a profound social dimension. In his work Pedagogy of the Oppressed, he suggests the ways in which teachers and social workers can strengthen and liberate the people oppressed by political, economic, social or ideological power structures (Janebová, 2014 , p. 71). Educational process in relation to the socially disadvantaged ones, e.g . Roma children, children of foreigners and the like, is the most important for this topic. If we want to improve the lives of socially disadvantaged people, it is also significant to work with the majority society. In this direction, developing multicultural education at Czech schools seems to be obvious. Young students and their teachers meet in person or through a delegated experience through their parents or more and more often through the media with excluded or otherwise weakened groups - e.g. refugees, immigrants, ethnic minorities, drug addicts and so on (Hrdá, Šíp et al., 2011, p. 7).

\section{Multiculturalism in school practice}

The starting point for social prevention in the context of social work in the educational process rests in the assumption that social events and social issues are more visible because of the challenges in the educational process of the client, therefore social problems are educationally determined (Machalová, 2013, p. 27). The most important attribute of a multicultural society is difference of individuals and groups. These may or may not be reflected in terms of physical differences, but always in terms of cultural differences. Members of different cultures have more or less different customs and habits, traditions, symbols, ceremonies and rituals, religion, as well as different languages, dialects, different ways of nonverbal communication, a different value system, etc. They are characterized by specific cultural patterns, i.e. using learned, more or less mandatory schemes in the form of specific customs, morals, laws and taboos for behavior in standard situations. Their knowledge, especially knowledge of intercultural differences in general is important for pedagogy. It is therefore possible to argue that multicultural education involves overcoming ignorance.

Ignorance is considered a factor that plays an important role in the creation and formation of prejudice. Measures that are not based on knowledge of life of those in concern have only a little chance for success (Giddens, 1999, p. 28). In the words of Geertz (2000, p. 24), ,to understand the culture of other people is to reveal their normality, while keeping in mind their uniqueness".

A key issue of the multicultural education at Czech schools is use of stereotypes and prejudices among teachers and their students. Prejudices and stereotypes are not a product of direct experience of the individual, they are irrational mostly adopted negative attitudes maintained by tradition directed toward someone or something. The subject of prejudice can be anything - a person or group of persons, things or events (Nakonečný, 1999, p. 223). In our society, a considerable amount of prejudice is related to Roma people.

Attitudes are generally internal dispositions of individuals to react to certain objects. By this term we mean sympathy or antipathy - affection or aversion towards objects, persons, groups and situations or other identifiable aspects of the environment, including abstract ideas and social policy (Atkinsonová, Atkinson et al., 1995, p. 727, Průcha, Walterová and Mareš, 2003, p. 171). Due to attitudes, we react in certain relatively stable manner. But it is essential that it should be possible to influence attitudes. The main and at the same time the most demanding 
educational goals influence values and attitudes.

The main aim of this investigation was to determine teachers and students attitudes towards people of different cultures. This was attained by examining educational programs that lead to conflict-free and peaceful co-existence of various groups with different cultures, ethnicity, religious beliefs, and others. It is however difficult to reveal the true attitudes of the respondents, especially when it comes to the attitudes towards people of different ethnicity and culture. The main research question was stated as follows: What are the attitudes of students and teachers in primary and secondary schools in Zlín, Olomouc and Moravia-Silesia Regions towards different ethnics, nationalities or cultural differences?

\section{Methodology}

This study used a descriptive survey design to examine the attitudes of students and teachers towards people of different ethnics, cultures and nationalities in Zlín, Olomouc and Moravia Silesia Regions. Gay (1981) defines descriptive survey design as a study where variables that exist have already occurred with non-intervention of researcher. Questionnaires were the main tools used for data collection in this study. Semi-structured interview guides were used to collect supplementary qualitative data from the teachers. A total of 228 and 915 questionnaires were successfully responded to by the teachers and students respectively. This quantitative data was cleaned and coded into statistical package for social sciences (SPSS) for analysis. SPSS was used to generate descriptive statistics such as frequencies, mean and standard deviation. Free answers of the respondents presented an addition to the quantitative research where the "hard" data met its limits considering the fact that the answers to the questions were not the only information the interviewer should record (Disman, 2008, p. 163; Švaříček, Šed'ová et al., 2014; Skutil et al., 2011).

The qualitative part of the data collection involved 30 teachers. Although the topic of the interviews was given in advance, as the selected technique of the semi-structured interviews suggests, teachers had the opportunity to express themselves to address individual questions. All the interviews were recorded on a dictaphone and then transcribed into a text document. A subsequent analysis was carried out in software for processing qualitative data Atlas.ti. Here, the transcribed conversations were subjected to open coding. Code groupings were then categorized according to their internal relationships, similarity or continuity and created 10 subcategories, from which 3 main categories were developed within the process. These include the categories of Multicultural Education, Roma and School and Influences Outside School.

\section{The results of the qualitative part of the research}

Teachers understand multicultural education primarily as an education to tolerance in relation to other cultures. Almost all teachers considered this topic highly relevant in our society, because, according to them, we would meet members of various ethnic groups more and more often in the Czech Republic. Teacher18 expressed the opinion as follows: „By the way the world gets smaller, more global and more and more people emigrate and come into contact with people of different faiths, different races". However, some teachers do not share this opinion, for example Teacher 29: "I think it is generally understood as the coexistence of different nationalities, eventually races in some countries. This does not concern us. It concerns our country in limited extent in comparison with, for example, 
America". This view, however, occurred rarely in the interviews. There is a general consensus among teachers that with the help of multicultural education, the relations among various cultures should develop.

Teacher 16: „Because I think that our society is extremely xenophobic, not only to the Roma, but in general to other nationalities, we are bothered by the Vietnamese because they take our jobs, as well as the blacks with whom we are not satisfied, etc.",other respondents view the Czech society as intolerant as well. In their opinion, this situation could change slowly with the younger generation, which has more opportunities to meet people from other countries and cultures than there were before. Some topics may be seen as controversial because young students use the opinion background from their families, which can be significantly questioned within the discussion. The Roma issue may serve as a specific example. In some of the regions where the interviews were implemented, the young students meet members of the Roma ethnic group more often, they have personal experience with them, or an intermediated experience provided by family or friends, which motivates them discuss this topic with the teachers more often. On the other hand, the motivational element is often a source of problem for many teachers, because they are not sure how to approach this issue, as they have learnt it contradicts the opinions and personal experience of young students.

For example, Teacher 1 analyzes the young students' opinion of the Roma, which is in his view strongly negative. „98\% of their opinions are negative. It can be very difficult to react to this at the lessons, because almost all of them have had some negative experience". When questioned about how the teacher could respond this situation, the response sounded like this: „Well look, I come into contact with them here, let's say, for two hours a week, and they live there among the community 24 hours a day, except for the time they are at school. So it is very difficult to interpret it."

Teacher 5 is of opposite opinion, he sees multicultural education as a tool to combat stereotypes in the case of young students. "The young students are aware of living in a greenhouse constructed by their parents, in certain stereotypes, and we must always learn to somehow overcome the stereotypes. Unfortunately, we are part of a globalized world, so this is a sort of biggest advantage of any kind of teaching of multiculturalism or simply learning discussion on certain issues." But, like most teachers, he also adds that the central motif of multicultural education at schools should be ,learning tolerance".

Most often, teachers agree that the main mission of multicultural education should be to encourage young students to learn about different cultures, which according to them have other features than the culture in which the young students grow up. Firstly to provide for a shift of their attitudes and values towards development of their tolerance and respect when concerned with the phenomena of otherness. Physical difference of ethnics is considered the most important feature of otherness by teachers. The accented groups which must be learned to tolerate are most often in the views of teachers Roma and Vietnamese. Other ethnics and nationalities are not considered to be as interesting from the teacher's perspective. They are represented by the concepts of ,other cultures“, „foreigners" and the like.

Roma as the topic of multicultural education were detected in all the interviews, we can therefore conclude that the understanding of multicultural education by teachers is closely linked to the topic of inclusion of young Roma students to schools, and generally of Roma into society. In this respect, the issue of the so-called socially excluded localities and impact on the coexistence of 
majority vs. minority that is perceived as problematic, due to the different social levels of marginalized population was mentioned.

On the other hand, teachers almost did not mention other ways of otherness with which students can meet, the diversity of genders, issues of different sexualities, physical differences caused by, for example, illness, or even the simple differences between the young students, which may be caused, for example, by different social background or other education. These need to be seen as separate individuals (cf. intercultural approach in Sleeter, Grant, 2009, p. 33; Banks, Banks, 2009, p. 22-23; DomNwachukwu, 2010, p. 5).

\section{The results of the quantitative part of the research}

From the theoretical basis of the suggested issue resulted the following research questions, which should confirm or disprove the following hypotheses:

- Coexistence of the majority with the Roma minority is problematic.

- Otherness is seen as a source of xenophobia and racism.

- The most common form of otherness reflected as a negative stigma is the Roma origin of its bearers.

The research questions were dealing with the challenges of the demand for a description of various forms of diversity in our population, namely foreigners, representatives of religious minorities and ethnic minorities in our country. The previous studies were implemented primarily by identifying value orientation and attitudes of young students and their teachers.

\section{Values of young students and teachers in relation to otherness}

In one of our closed scale questions, there was examined the importance of the submitted values. Our aim was to compare the result of the value orientation of the respondents with the answers we obtained in reaction to the issues relating to otherness.

The young students chose Friendship and fellowship as the most important values in $71.6 \%$ and as rather important in further 19.8\%. Furthermore, the respondents chose the value of Love and partnership as the most important in $66.6 \%$ and rather important in $22.2 \%$. Tolerance to different sexual orientation was mostly categorized as of little importance in $10.8 \%$ and in $8.2 \%$ as the least important.

Teachers marked mostly Love and partnership (63\%), Sense of justice (60.8\%) and Friendship and fellowship (55.5\%) as the most important values. The most preferred values also included the Ability to communicate (the sum of the answers the most important and quite important amounted to 95.2\%), the Ability to help the ones in need (92.9\%), Tolerance to high age and the elderly (91.1\%), and Protection of the disadvantaged ones (89.8\%). The categories Recognition of the majority (17.9\%), Tolerance to different sexual orientation (8.9\%) and Tolerance to different appearance (8\%) were marked as of little or the least importance.

In the case of teachers, as well as in the case of young students, all the evaluated values relate to personal relationships among individuals. Less appreciated values appear to be related to general tolerance to otherness, unique identity of persons and their mutual differences, which include different sexual orientation, different appearance and so on.

\section{The relationship of respondents to otherness}

We asked our respondents by the means of a semi-closed question about their personal relationship to various ethnic or cultural groups. 
Graph 1: The importance of values in the case of young students
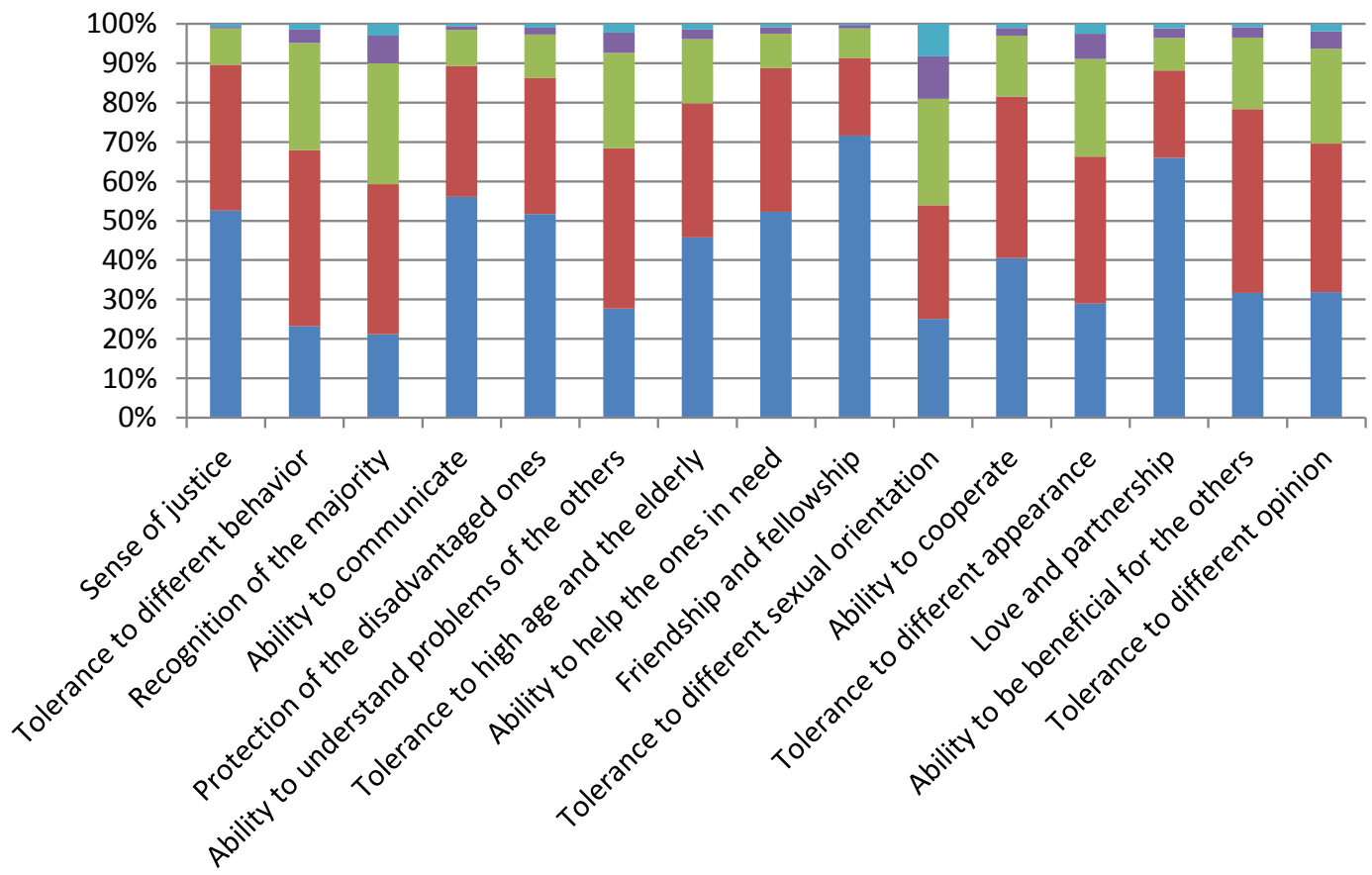

$\square$ The most important $\square$ Quite important $\square$ Important $\square$ Not very important $\square$ The least important

Graph 2: The importance of values in the case of teachers

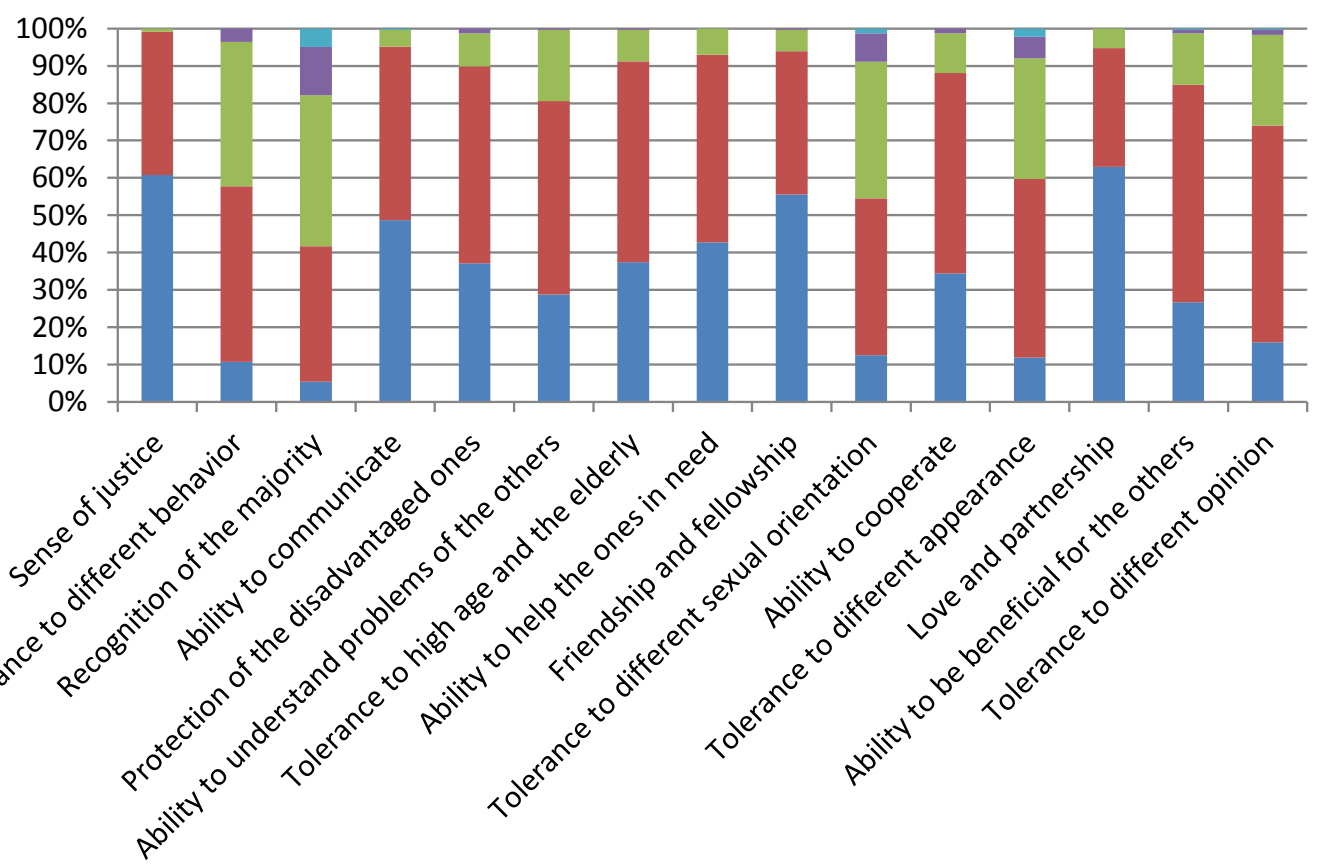

The most important $\square$ Quite important $\square$ Important $\square$ Not very important $\square$ The least important 
Graph 3: The relationship of young students to different ethnic groups

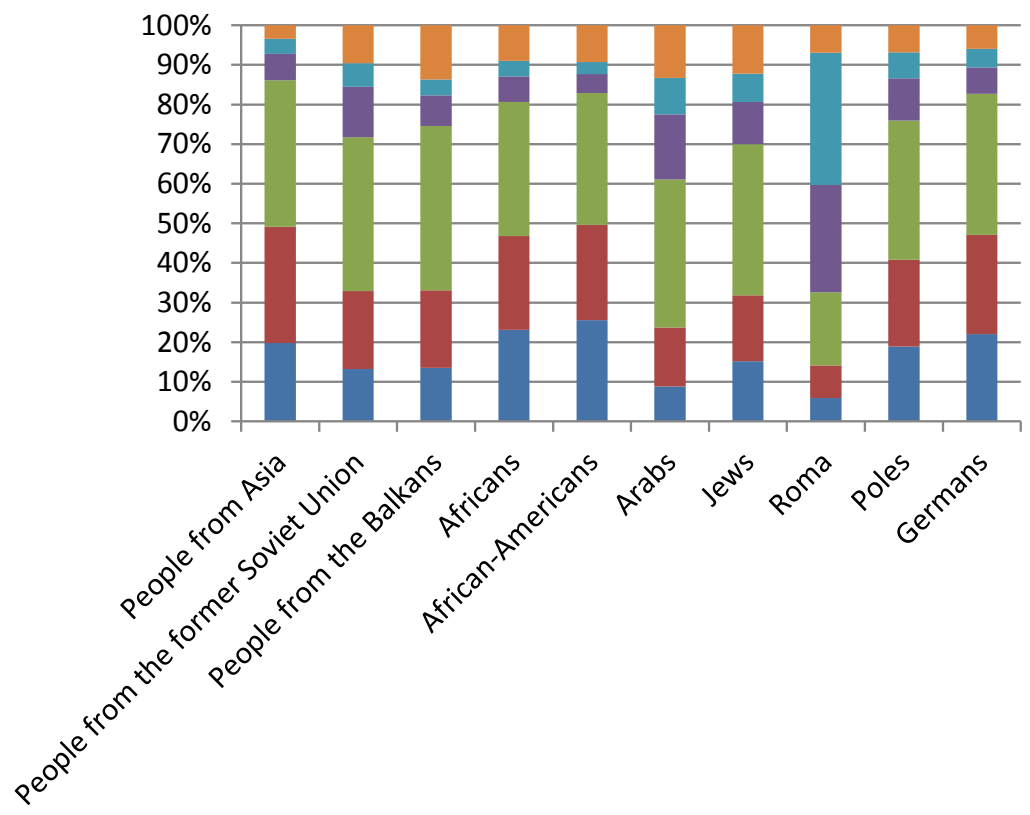

- I do not know, I do not have any opinion on that

Definitely negative

Rather negative

Neutral (neither negative, nor positive)

Rather positive

Definitely positive

Graph 4: Relationship of teachers to different ethnic groups

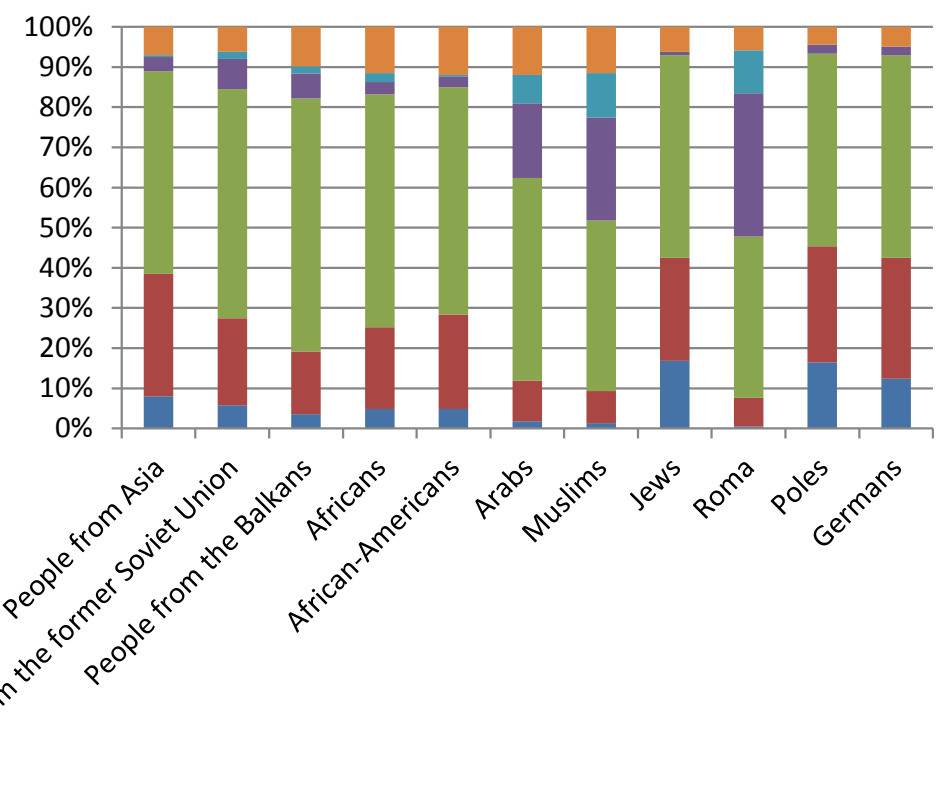

- I do not know, I do not have any opinion on that

Definitely negative

Rather negative

Neutral (neither negative, nor positive)

Rather positive

Definitely positive 
In the case of young students, it is quite obvious that the neutral and positive attitude to the relevant ethnic groups prevails over the negative ones, with one exception, which is the Roma. Also in the case of Arabs, the ratio of positive responses is one of the lowest ones.

Teachers evaluated their attitudes to the majority of the groups in relation to which they could express their opinions mostly as neutral and positive ones (although it occurred in a lesser extent than in the case of young students), which outweighed the negative ones. They usually justified their attitude by lack of knowledge of the group in concern or its members as the reason why they could not opt for one of the more clearcut answers.

Our respondents evaluated their personal relationship to different ethnic groups in general in a very similar way. Young students chose a neutral standpoint in $46.2 \%$ of cases, the quite positive one in $17.1 \%$ and $13.3 \%$ chose the option that they had no opinion. Teachers marked their relationship with members of other ethnic groups or cultures as neutral in $60 \%$, positive in $29.3 \%$ and negative in $8.8 \%$ of cases. The question was designed as a closed one with reasoning in the form of verbal commentary. In the respondents' answers there occurs a particularly prevalent emphasis on the willingness of different ethnic groups to adapt, to behave according to the regulations acknowledged in the Czech Republic (,It depends on the behavior, the willingness to adapt $\left.{ }^{6}\right)$. These responses constitute $22.1 \%$ in the case of young students. $34.3 \%$ of teachers inclined to the opinion that it depends on the behavior of individual people. Respondents then usually reflected their personal experience in their decisions, even if it was absent $(21.9 \%$ of teachers and $8.1 \%$ of young students). Especially young students frequently expressed their disinterest in the issue.

Relationship of adolescents to otherness is also documented within the statements of respondents related to what they consider attractive about foreigners and on the contrary, what bothers them about foreigners. Mainly cultural customs and traditions

\section{Graph 5: What I like about foreigners / what bothers me about them}

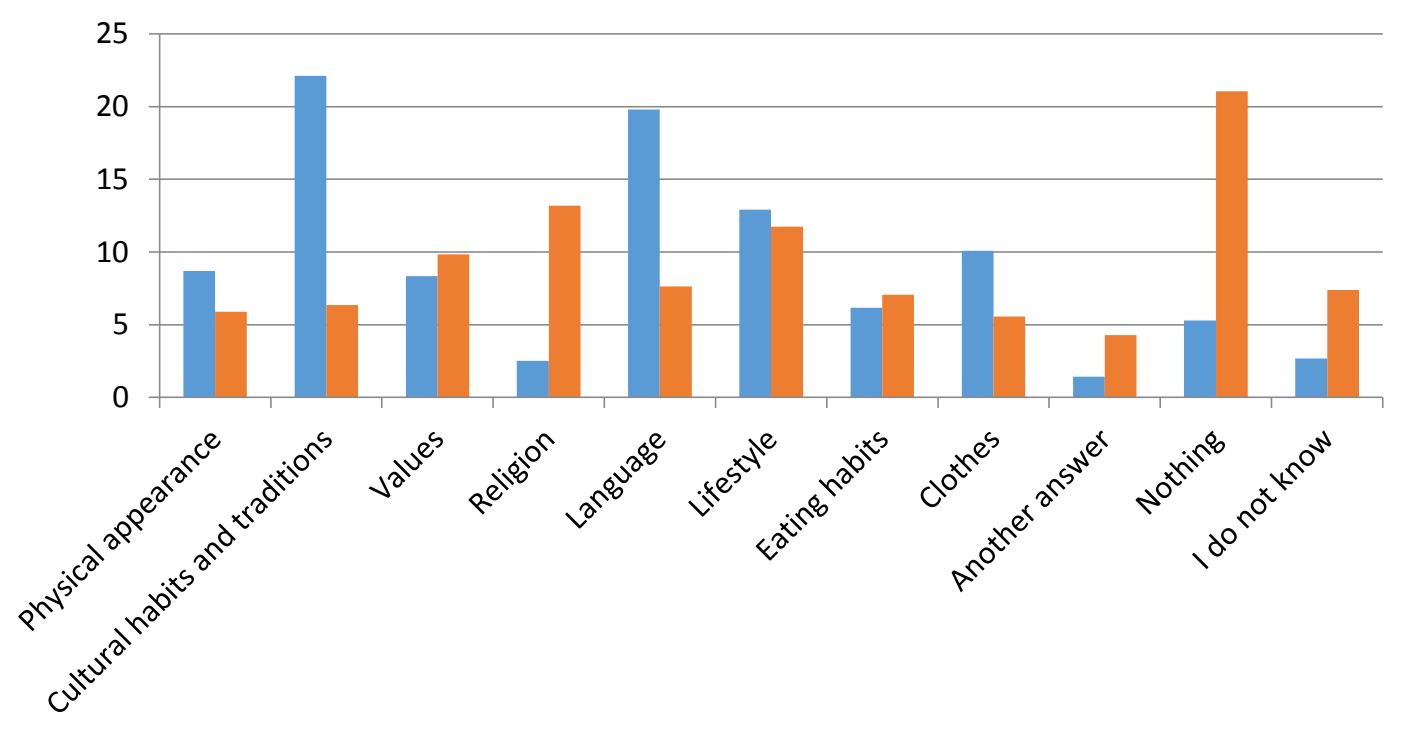

I like it about foreigners $\quad$ It bothers me about foreigners 
(22.1\%), language (19.8\%) and lifestyle $(12.9 \%)$ were evaluated positively.

A similar question was also used to define the extent to which young students' fear of foreigners was justified. The opinion that fear of foreigners is justified prevailed in the highest frequency here, foreigners seems to denote certain danger to our society, or the few is at least understandable to a large extent.

Teachers were also asked if they considered foreigners beneficial to our society, or not. Neutral answers prevailed over the positive or negative statements in the case of teachers. Nevertheless, approximately $40 \%$ of the respondents consider foreigners beneficial to our society, which is in correlation with the fact that $44 \%$ of teachers do not consider foreigners a risk to our society.

The respondents' answers absolutely obviously show that neutral and positive attitude to the relevant ethnic groups prevails over negative attitudes, even in case of Arabs, where the ratio of positive responses is almost the lowest one.

\section{Graph 6: Fear of foreigners}

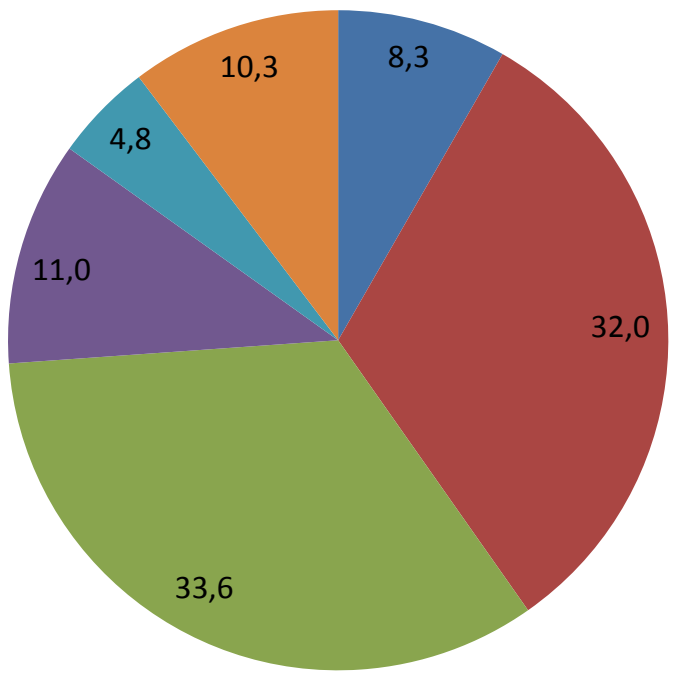

Questionnaires administered to the young students targeted their attitudes as well as that of their families towards the Muslims. The answers show that the young students consider the attitudes of their families and friends to Muslims to be neutral. In both cases, the neutral value possibility was chosen by more than $50 \%$ of respondents. In the case of personal views on Muslims, which respondents presented in an open question, $41.3 \%$ corresponded with the category of „I do not know, I do not have any opinion on that". Another $27.1 \%$ of respondents expressed a neutral attitude and $24.0 \%$ negative or rather negative one.

An exception, in which the evaluation was not mainly neutral and positive, concerned only one group, the Roma, in the case of which our respondents chose more often quite negative, or clearly negative attitude.

In $29.9 \%$ of cases, they talked about the behavior of the given group, as was in the case of a young student: ,It depends on who they are and how they behave". In other cases, respondents refer directly to the specific 
the behavior of the Roma as such, most often with negative connotations: "I think they don't have any manners and I don't like their behavior". 21.1\% of respondents explained their attitudes by writing that the given group of people simply bothered them and in most cases without giving any reason, as it is evident here: ,And you ask why??? Yuck," wrote a young student.

\section{Conclusion}

From the results of our research, it is apparent that teachers at Czech schools may not function sufficiently as assistants and guides to the young students - individuals or groups, who need social assistance because they belong to a marginalized group that is excluded or socially impaired - on their way to adapt to the mainstream society of the white majority. It seems that a space for a social worker as a social educational advisor (according Machalová) or social teacher (according Gulová, Hrdá, Šíp etc.) is open here. Our assumptions were confirmed in the case of a lower degree of tolerance of adolescents to the Roma minority compared to the other ethnic or cultural minority groups. The assumption that teachers and young students perceive coexistence of the majority with Roma minority as problematic has been confirmed. The research shows that attitudes declared by both young students and teachers may to some extent reflect the inclination of their bearers to xenophobia and racism as the stigmatization of the Roma in the public space of the Czech Republic is widely shared.

Based on our research, we may conclude that the values and attitudes of adolescents focused on their perceptions of members of different cultures and ethnicity is entirely different from the values and attitudes of their teachers.

Different ethnic groups are generally perceived as homogeneous entities cul- turally distinct from the majority and thus bearing the hallmark of ,otherness“ closely associated with stereotypical notions about the members of these groups. Such an approach is problematic because it goes against the spirit of multicultural education, which should eliminate stereotypes.

It is the very misunderstanding and unwillingness to try to understand the ,normality of otherness", as well as a lack of effort not to designate otherness as something special, that significantly are the source of the ambivalent attitude of our respondents towards the members of minority groups.

\section{References}

ATKINSON, R. L. - ATKINSON, R. C. et al. (1995) Psychology. Prague: Viktoria Publishing, 1995.

BANKS, J. A., BANKS, C. A. M. (2009) Multicultural Education: Issues and Perspectives. 7th Ed. San Francisco: John Willey \& Sons, 2009.

DISMAN, M. (2008) How To Make Sociological Knowledge. 3rd Ed. Prague: Karolinum 2008.

DomNWACHUKWU, Ch. S. (2010) An Introduction to Multicultural Education. Lanham: Rowman \& Littlefield Publishers, 2010.

FREIRE, P. (1986) Pedagogy of the oppressed. 3rd Ed. New York: Continuum, 1986.

GAY, L, R. (1981) Educational research; Competencies for analysis and application. 2nd Ed. Columbus, OH: Charles e. Merrill, 1981.

GEERTZ, C. (2000) The Interpretation of Cultures: Selected Essays. Prague: SLON, 2000.

GIDDENS, A. (1999) Sociology. Prague: Argo, 1999.

HRDÁ, M. - ŠÍP, R. et al. (2011) Identity in Social-Pedagogical Research. Brunn: Masaryk University, 2011.

JANEBOVÁ, R. (2014) Critical social work. Prague: Gaudeamus, 2014.

MACHALOVÁ, M. (2013) Preventive 
Social Work. Educational Paradigm in the Social Work. Presov: University of Presov, 2013.

NAKONEČNÝ, M. (1999) Social psychology. Prague: Academia, 1999.

PRŮCHA, J. - WALTEROVÁ, E. MAREŠ, J. (2003). Pedagogical Dictionary. 4th Ed. Prague: Portal, 2003.

SKUTIL, M. et al. (2011) Basics of Educational-Psychological Research for Students of the Teaching Profession. Prague: Portal, 2011.

SLEETER, Ch. E. - GRANT, C. A. (2009) Making Choices for Multicultural Education. Five Approaches to Race, Class, and Gender. 6th Ed. New York: John Willey \& Sons, 2009.

ŠVAŘÍČEK, R. - ŠEĎOVÁ, K. et al. (2014) Qualitative Research in Pedagogical Sciences. 2nd Ed. Prague: Portal, 2014.

\section{Corresponding author}

doc. Mgr. Martina Cichá, Ph.D.

Department of Anthropology and Health Education, Faculty of Education, Palacký University Olomouc,

Žižkovo nám. 5, 77147 Olomouc,

CZECH REPUBLIC

e-mail: martina.cicha@upol.cz

\section{Mgr. Andrea Preissová Krejčí, Ph.D.}

Department of Anthropology and Health Education, Faculty of Education, Palacký University Olomouc,

Žižkovo nám. 5, 77147 Olomouc,

CZECH REPUBLIC

e-mail: andrea.preissova@upol.cz 